\title{
Assistência ao parto sob a ótica de enfermeiras obstétricas
}

\section{Labor assistance from the perspective of obstetrical nurses}

\section{Asistencia al parto bajo la óptica de enfermeras obstétricas}

Recebido: 03/08/2018

Aprovado: 28/02/2019 Publicado: 01/07/2019
Larissa de Oliveira Peripolli ${ }^{1}$ Marcelexandra Rabelo ${ }^{2}$ Silvana Regina Rossi Kissula Souza ${ }^{3}$ Marilene Loewen Wall ${ }^{4}$ Tatiane Herreira Trigueiro 5 Karin Madeleine Godarth ${ }^{6}$

O objetivo deste estudo foi avaliar a atuação de enfermeiras obstétricas em uma maternidade de risco habitual por meio de indicadores de assistência obstétrica, bem como conhecer a visão dessas profissionais sobre a inserção de suas atividades nos processos de parto. Trata-se de pesquisa avaliativa, descritiva, de abordagem mista, realizada a partir dos indicadores de assistência referentes ao período de maio de 2014 a dezembro de 2015, e de entrevistas realizadas com cinco enfermeiras obstétricas atuantes na assistência ao parto em maternidade de risco habitual em Curitiba, Paraná. A coleta ocorreu entre agosto e outubro de 2016. Os indicadores foram analisados com base em estatística simples e as entrevistas por meio de análise temática. A inserção de enfermeiras obstétricas promoveu a redução de práticas consideradas prejudiciais na assistência ao parto, gerando um impacto positivo na mudança do modelo de atenção da instituição.

Descritores: Enfermagem Obstétrica; Cuidados de enfermagem; Parto humanizado; Humanização da assistência; Obstetrícia.

The aim of this study was to evaluate the assistance of the obstetric nurses in a normal-risk maternity assistance through indicators of obstetric care, as well as to know their perspective about their insertion in the labor process. This is an evaluative and descriptive study using a mixed approach based on the assistance indicators for the period from May 2014 to December 2015, and data from interviews with five obstetric nurses working in normal-risk maternity care at Curitiba, Paraná, Brazil. The data collection occurred between August and October 2016. The indicators were analyzed through descriptive statistics and the interviews through thematic analyses. The insertion of the obstetric nurse promoted reduction of practices considered harmful during labor assistance, generating positive impacts on the change of the care model of the institution.

Descriptors: Obstetric Nursing; Nursing care; Humanizing delivery; Humanization of assistance; Obstetrics.

El objetivo de este estudio fue evaluar la actuación de la enfermera obstétrica en una maternidad de riesgo habitual por medio de indicadores de asistencia obstétrica, así como conocer la visión de estas sobre su inserción en el proceso del parto. Se trata de una investigación evaluativa, descriptiva, de abordaje mixto, realizada a partir de los indicadores de asistencia referentes al periodo de mayo de 2014 a diciembre de 2015 y de entrevistas realizadas con cinco enfermeras obstétricas actuantes en la asistencia al parto en maternidad de riesgo habitual de Curitiba, Paraná, Brasil. La colecta ocurrió entre agosto y octubre de 2016. Los indicadores fueron analizados a través de estadística simple y las entrevistas por medio de análisis temático. La inserción de la enfermera obstétrica promovió reducción de prácticas consideradas perjudiciales en la asistencia al parto, generando impacto positivo en el cambio del modelo de atención de la institución.

Descriptores: Enfermería Obstétrica; Atención de enfermería; Parto humanizado Humanización de la atención; Obstetricia.

1. Enfermeira Obstétrica do Hospital de Clínicas da Universidade Federal do Paraná (HC-UFPR). Mestranda em Enfermagem pelo Programa de Pós-Graduação em Enfermagem (PPGE) da UFPR, Curitiba, PR, Brasil. ORCID: 0000-0003-0582-874X E-mail: lperipolli@gmail.com

2. Enfermeira Obstétrica do HC-UFPR. Mestre em Enfermagem. Curitiba, PR, Brasil. ORCID: 0000-0002-0291-5373 E-mail: marcelexandrar@gmail.com

3. Enfermeira Obstétrica. Mestre em Engenharia de Produção. Doutora em Ciências. Coordenadora do Curso de Especialização em Enfermagem Obstétrica Rede Cegonha/UFMG/UFPR. Professora pelo PPGE-UFPR, Curitiba, PR, Brasil. ORCID: 0000-0002-1679-4007 E-mail: skissula@ufpr.br

4. Enfermeira Obstétrica. Mestre e Doutora em Enfermagem. Professora pelo PPGE-UFPR, Curitiba, PR, Brasil. ORCID: 0000-0003-1839-3896 E-mail: wall@ufpr.br

5. Enfermeira Obstétrica. Mestre em Enfermagem. Doutora em Ciências da Saúde. Professora pelo Departamento de Enfermagem da UFPR, Curitiba, PR, Brasil. ORCID: 0000-0003-3681-4244 E-mail: tatiherreira@ufpr.br

6. Enfermeira Obstétrica. Mestranda em Enfermagem pelo PPGE/UFPR. Presidente da Associação das Enfermeiras Obstétricas (ABENFO) Seção Paraná, Curitiba, PR, Brasil. ORCID: 0000-0002-9240-0591 E-mail: kmgodarth@gmail.com 


\section{INTRODUÇÃO}

$\mathbf{0}$ modelo de atenção obstétrica e neonatal no Brasil é predominantemente tecnocrático, o que vem sendo cada vez mais discutido no cenário da saúde. Com os altos índices de morbimortalidade materna e infantil e as constantes tentativas de encontrar soluções para a redução destes números, a medicalização e a instrumentalização da assistência ao parto vêm sendo cada vez mais discutidas ${ }^{1}$.

No modelo tecnocrático, os processos de gestar e parir são vistos e estudados como eventos patológicos. 0 corpo da mulher é entendido como incapaz de dar conta do desenvolvimento do bebê e, principalmente, de se responsabilizar pelo processo do parto, fazendo com que a equipe de saúde assuma o protagonismo do nascimento e, portanto, colocando a mulher em uma posição de vulnerabilidade, insegurança e infantilização ${ }^{1}$.

Compreendendo esse modelo de atenção e os prejuízos que vêm sendo impostos na assistência em decorrência dele, torna-se necessário expandir o olhar sobre a atenção obstétrica, recorrendo aos modelos humanista e holístico da atenção perinatal, uma vez que o parto deve ser entendido como um evento fisiológico ${ }^{1}$.

As políticas públicas de saúde da mulher vêm sendo discutidas pelo Ministério da Saúde (MS) desde 1930, quando a mulher ainda era tratada a partir de uma visão reducionista ${ }^{2}$. Com a evolução das políticas públicas e almejando a redução da morbimortalidade materna e infantil, o MS lançou em 2011 a Rede Cegonha (RC), propondo uma rede de cuidados com a saúde materna e infantil, visando garantir à mulher o acesso ao planejamento reprodutivo, bem como à gestação, ao parto e ao puerpério humanizados e de qualidade ${ }^{3}$. Esta política também visa garantir à criança o nascimento seguro, bem como crescimento e desenvolvimento saudáveis até os vinte e quatro meses de vida ${ }^{3}$.

É possível entender a RC como uma política pública para incentivar a mudança no modelo de atenção obstétrica, uma vez que ela reforça em seu componente II, Parto e Nascimento, a adoção das Boas Práticas de atendimento ao parto ${ }^{3}$ com base no informe Maternidade Segura, que foi elaborado pela Organização Mundial da Saúde (OMS) ${ }^{4}$ e classifica algumas práticas em categorias de acordo com o nível de evidências científicas (Categoria A - Práticas demonstradamente úteis e que devem ser estimuladas; Categoria B Práticas claramente prejudiciais ou ineficazes e que devem ser eliminadas; Categoria C Práticas em relação às quais não existem evidências suficientes para apoiar uma recomendação clara e que devem ser utilizadas com cautela, até que mais pesquisas esclareçam a questão; e Categoria D - Práticas frequentemente utilizadas de modo inadequado).

Dentre as várias recomendações da RC referentes ao Componente II, estão o estímulo à implementação de equipes horizontais do cuidado nos serviços de atenção obstétrica e neonatal e a inserção de enfermeiras obstétricas na assistência ao parto e nascimento ${ }^{3,4}$, de forma que a profissão vem conquistando visibilidade no cenário da saúde, devido às crescentes discussões acerca da assistência humanizada ao parto.

Dentre algumas das atribuições desta (e) profissional estão a realização da consulta de enfermagem obstétrica, o acompanhamento do trabalho de parto, o atendimento ao parto domiciliar planejado, o atendimento ao parto hospitalar de risco habitual e o acompanhamento tanto da mulher, quanto do recém-nascido (RN) no período pós parto ${ }^{5}$.

Nesse sentido, o objetivo do estudo foi avaliar a atuação de enfermeiras obstétricas em uma maternidade de risco habitual por meio de indicadores de assistência obstétrica, bem como conhecer a visão dessas profissionais sobre a inserção de suas atividades no processo de parto.

\section{MÉTODO}

Trata-se de uma pesquisa avaliativa, descritiva de abordagem mista, realizada em uma maternidade pública de Curitiba, integrada ao Programa Mãe Curitibana e referência para o atendimento de mulheres em gestação de risco habitual.

0 método misto faz uso de elementos quantitativos e qualitativos, permitindo assim unir diferentes tipos de dados em prol de um único estudo ${ }^{6}$. Para este alcance, a pesquisa foi dividida em duas etapas de coleta e análise.

A primeira etapa foi a quantitativa, na qual foram coletados os indicadores da assistência obstétrica monitorados pela gestão da maternidade durante o período de maio de 2014 a dezembro de 2015. As informações foram obtidas por meio de planilhas secundárias disponibilizadas pela gestão do serviço e organizadas no programa Microsoft Office Excel®. Os dados foram coletados no período de agosto a outubro de 2016, analisados por meio de estatística simples e posteriormente demonstrados em gráficos.

$\mathrm{Na}$ segunda etapa realizou-se a coleta das entrevistas com as cinco enfermeiras obstétricas que compõem o quadro funcional da instituição. Todas elas atuam na assistência direta ao parto e nascimento. Para a composição da amostra foram considerados os seguintes critérios de inclusão: estar na maternidade no período da coleta de dados e atuar na assistência direta ao parto. 
Os critérios de exclusão foram os seguintes: estar em período de licença, afastamento ou férias na ocasião da coleta de dados; exercer outras funções (cargo de gerência, educação continuada, e outros). Esse último critério foi adotado para priorizar as opiniões das profissionais que compõem a equipe assistencial e vivenciam a prática da obstetrícia em seu dia-a-dia.

As entrevistas foram realizadas entre agosto e novembro de 2016, durante o expediente de trabalho das enfermeiras, com autorização da coordenadora de enfermagem e em sala privativa, onde foi realizada a leitura do Termo de Consentimento Livre e Esclarecido (TCLE). As entrevistas foram gravadas em áudio e realizadas a partir da seguinte pergunta: "Como você percebe a sua atuação na assistência ao parto e nascimento, bem como seu papel na mudança do modelo de atenção?"; posteriormente, foi realizada a transcrição do material.

Para o tratamento dos dados foi utilizada a análise de conteúdo proposta por Bardin. Esse método consiste em extrair informações do conteúdo enunciado no processo de comunicação e contempla três momentos: préanálise, exploração do material e tratamento dos resultados, inferência e interpretação dos resultados 7 .

Neste estudo foram atendidos os aspectos éticos e normativos para pesquisas com seres humanos, de acordo com a Resolução n. ${ }^{0466 / 2012}$. 0 projeto foi aprovado pelo Comitê de Ética em Pesquisa da Secretaria Municipal de Saúde de Curitiba, segundo o Parecer $\mathrm{n}$ o 1.608.184. Para garantir o anonimato, as participantes foram codificadas conforme a ordem de coleta das entrevistas: E01, E02, E03, E04 e E05.

\section{RESULTADOS}

$\mathrm{Na}$ etapa quantitativa são apresentados os dados dos anos de 2014 e 2015 referentes à média anual de cada indicador. Os gráficos foram apresentados conforme as Boas Práticas propostas pela Organização Mundial da Saúde4. 0 total de partos vaginais atendidos em $2014 \mathrm{e}$ 2015 foram $n=1662$ e $-n=1456$, respectivamente.

Na Figura 1 é possível observar a média dos indicadores referentes às práticas que devem ser eliminadas ou revistas pelos profissionais, enquanto a Figura 2 demonstra os indicadores de práticas benéficas e que devem ser estimuladas.

Figura 1. Média anual de indicadores conforme categorias ' $B$ ', 'C' E 'D' das Boas Práticas e Rede Cegonha. Curitiba, Paraná. 2014 e 2015.

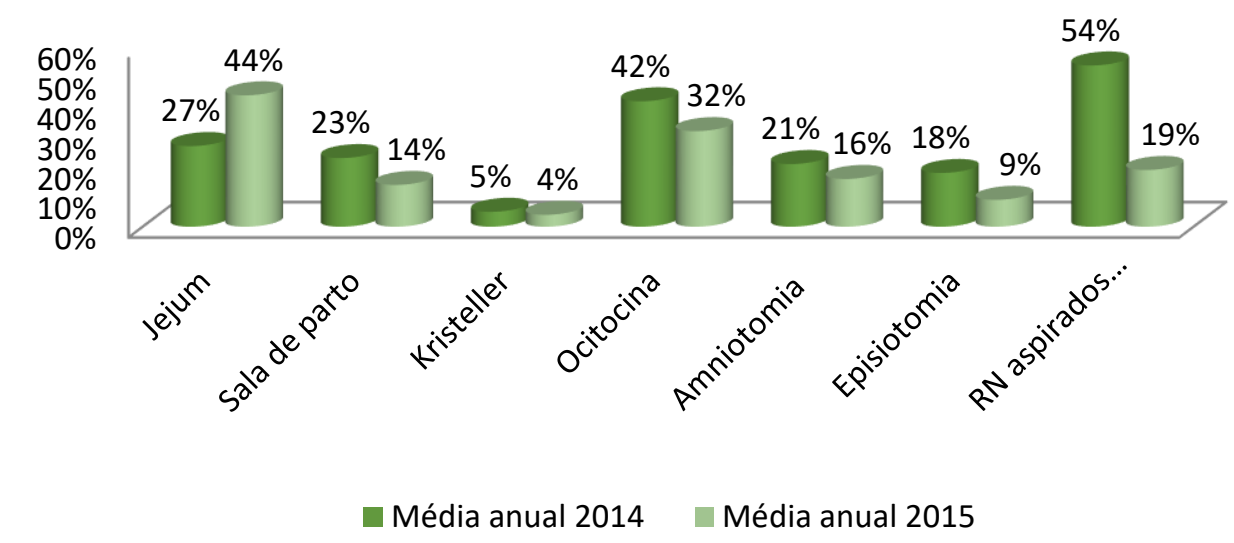

Figura 2. Média anual de indicadores conforme categorias 'A' e 'D' das Boas Práticas e Rede Cegonha. Curitiba, Paraná. 2014 e 2015.

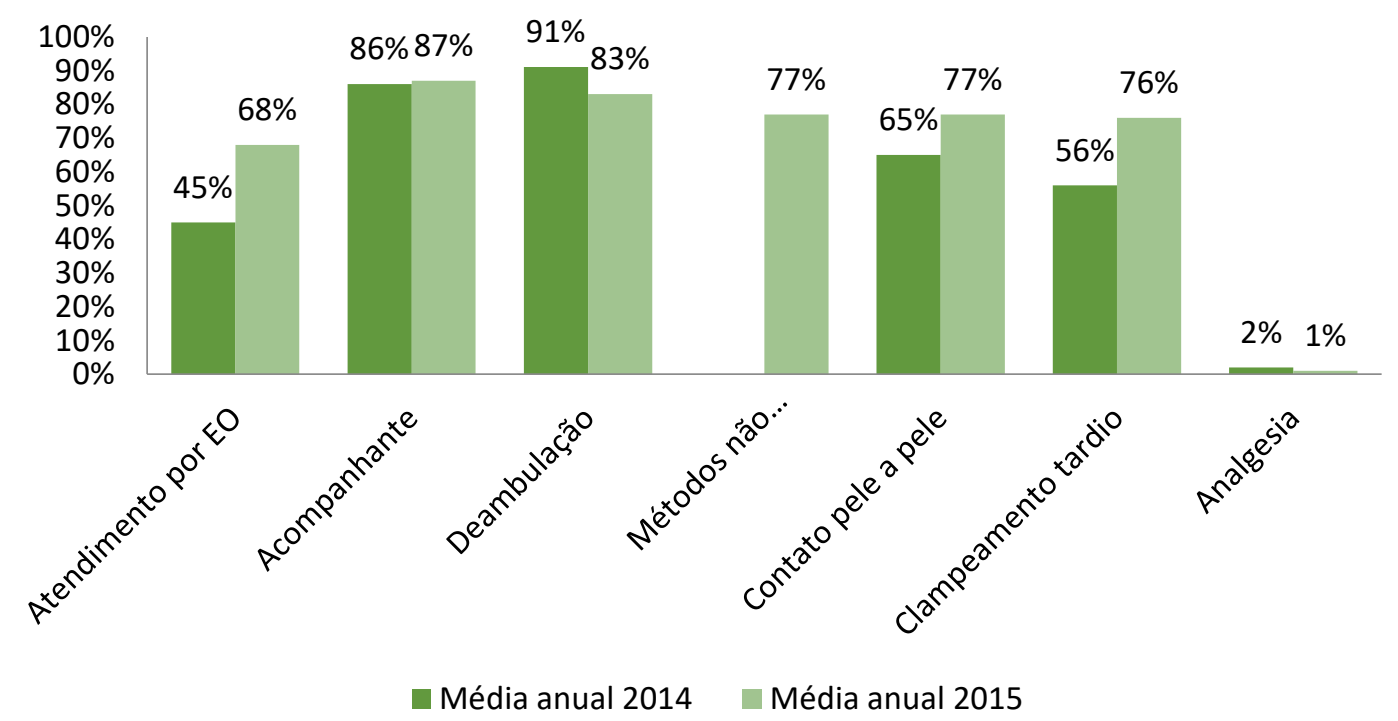


$\mathrm{Na}$ etapa qualitativa emergiram as seguintes categorias: Formação, Mudança de modelo assistencial, Postura ético-profissional e Protagonismo da mulher no parto. A seguir, serão elencadas algumas falas que auxiliaram na definição dessas categorias.

\section{Formação}

Nesta categoria foram identificadas as seguintes falas:

[...] a nossa própria formação ela já é diferenciada com uma visão mais holística da mulher [...] essa mudança [mudança do modelo de atenção] é muito de formação também. E é uma mudança difícil, porque a medicina é formada para atuar, é formada para intervir; e a gente como enfermeiro não é formado só para isso (E01);

[...] porque o profissional médico já foi treinado para intervir, e nós já fomos preparadas de uma forma diferente (E02);

[...] E a tendência, pelo menos na nossa formação, acho que de todas as enfermeiras aqui da maternidade, a tendência é que a gente atenda o parto de maneira mais natural, respeitando a fisiologia do corpo feminino (E03).

\section{Mudança de modelo assistencial}

Identificou-se algumas falas:

[...] por isso que essa mudança é bem difícil, bem gradual, é angustiante (risos) [...] se não houver uma visão diferente do processo não tem mudança. (E01);

Eu acredito que a gente veio realmente para fazer essa mudança do modelo né [...] eles [os médicos] não respeitam a mulher como protagonista [...] $O$ importante para eles é que mulher e bebê saiam vivos na sua maioria [...] mas eu acho que até mesmo com a nossa inserção nesse modelo a gente acaba influenciando a mudança dos médicos. (E02);

Sem a atuação dela [enfermeira obstétrica] o modelo seria ainda aquele tradicional, porque é muito difícil mudar a cabeça dos médicos que já tão aí há 30 anos assistindo parto da mesma forma e acreditam que só existe aquele jeito de conduzir tudo [...] (EO5).

\section{Postura/ética profissional}

Esta categoria apresentou as seguintes narrativas:

[...] a gente tem que tá lutando cada dia, porque cada dia vai surgir novos conflitos. Conflitos talvez pessoais, não é nem de condutas, por visão de postura mesmo do profissional. Pelo profissional que ele tá mudando por uma obrigação e não pelo melhor atendimento à mulher (E01); [...] para os enfermeiros obstetras que tão afim de... que acreditam que a mudança do modelo é o melhor para a mulher, implantar todas as medidas que a Rede Cegonha preconiza [...] enfim, aqueles que estão dispostos a fazer isso [...] eles são fundamentais (E03);

Eu tento conhecer muito a personalidade de cada um [dos médicos] ao invés de bater de frente, porque é pior, aí eles [os médicos] vão ficar com raiva de mim e vão descontar na paciente (E05).

\section{Protagonismo da mulher no parto}

Observou-se as seguintes falas:

[...] a gente consegue deixar a mulher como protagonista do processo, entendendo o ser como holístico e não só como um procedimento hospitalar [...] (E01);

Se muitos profissionais colocassem em primeiro lugar o respeito da mulher eu acho que todo mundo ia conseguir fazer uma assistência adequada [...] Acima de tudo sempre procurar respeitar os desejos [...] hoje já trabalham muito com a questão do plano de parto, muitas já vem bem orientadas para a maternidade, então a gente procura sempre seguir, discutir [...](E04);

[...] tenho o princípio de deixar a paciente muito à vontade. Atender muito a vontade dela, não forçar ela a fazer nada que ela não deseje [...] acho que orientação é o primeiro passo para tudo. Acho que quando você recebe uma paciente bem orientada, a condução do trabalho de parto é totalmente diferente de quando você recebe uma paciente amedrontada, assustada, com pouca ou sem nenhuma informação [...] o trabalho de parto acho que evolui de uma forma melhor [...] (E05).

\section{DISCUSSÃO}

Os dados quantitativos possibilitaram comparar os indicadores conforme as Boas Práticas recomendadas pela $\mathrm{OMS}^{4}$. Estão enquadrados na Categoria $\mathrm{A}$ os seguintes indicadores: presença do acompanhante, contato pele a pele imediato e o clampeamento tardio do cordão umbilical. A taxa de mulheres que tiveram a presença do acompanhante apresentou-se linear, permanecendo acima de $85 \%$, fato que pode estar relacionado à Lei do Acompanhante $^{8}$, uma vez que esta foi sancionada no ano de 2005 e, portanto, já era uma prática da maternidade.

Quanto ao contato pele a pele e o clampeamento tardio do cordão, é recomendado na Portaria no 371 , de 7 de maio de 2014, em seu artigo 4o que, para o recémnato com padrão respiratório normal, tônus normal e sem líquido amniótico meconial, sejam asseguradas essas práticas 9.0 início do monitoramento desses indicadores na maternidade coincidiu com a publicação da Portaria. Porém, apenas no ano de 2015 observou-se o aumento das taxas, o que pode estar relacionado ao tempo de adaptação levado pela equipe para se adequar às normas previstas na legislação.

Ao observar os índices da taxa de bebês aspirados (que apresentou uma queda de 35\%) de um ano para outro, pode-se inferir que o tempo de contato do bebê ao nascer, de ao menos uma hora com a pele da mãe, reduz o espaço para o mesmo ser levado para a sala de procedimentos e submetido à aspiração. Além disso, não existem evidências que demonstrem benefício na aspiração de RNs saudáveis e a termo ${ }^{10}$.

O uso excessivo de ocitócitos durante o trabalho de parto está relacionado com os internamentos precoces decorrentes do falso diagnóstico de trabalho de parto ${ }^{11}$. Durante o período do estudo foram reformulados os protocolos institucionais, os quais redefiniram os quesitos necessários para internamento, fato que pode ter impactado na diminuição de $10 \%$ do uso da ocitocina sintética para condução dos partos de um ano para o outro.

Em relação à manobra de Kristeller, pode-se afirmar que a mesma-prática vem sendo pouco utilizada na maternidade, quando se compara os dados coletados aos da Pesquisa Nascer no Brasil, por exemplo, que demonstraram que a região centro-oeste é a que mais pratica a manobra (45,5\%), e que ela é realizada em sua maioria-majoritariamente nas mulheres mais velhas e nas primíparas. A 
região Sul ocupa a última posição $(32,3 \%)^{12}$. Apesar de ter sido observada uma diminuição neste indicador, ficou demonstrado em revisão sistemática recente que não há evidências suficientes para recomendar a realização desta prática, uma vez que não há comprovação de benefício para o bem estar fetal e, apesar de não existirem tantos estudos, deve-se considerar ainda o risco de trauma perineal severo ${ }^{13}$.

A amniotomia está relacionada com o aumento no índice de cesarianas, e não apresentou diferença estatisticamente significante ao tempo de duração do trabalho de parto e vitalidade do bebê após o nascimento. Portanto, torna-se evidente que os índices dessa prática na maternidade devem ser revistos e discutidos entre equipe e gestão para adequação ao que apontam as evidências científicas $^{11}$.

Ainda que a $\mathrm{OMS}^{4}$ recomende o estímulo à oferta de líquidos por via oral durante 0 trabalho de parto e parto, o Brasil apresenta uma taxa de $74,4 \%$ das parturientes de risco habitual mantidas em jejum, sendo $78 \%$ delas referentes a parturientes da região Sul ${ }^{12}$. Ainda assim, esse indicador apresentou aumento de 2014 para 2015 na maternidade em estudo.

Como a maior parte das recomendações sobre jejum pré-anestésico se refere a cirurgias eletivas e sugere que devem existir protocolos específicos para a obstetrícia, a American Society of Anesthesiologists (ASA) ${ }^{14}$ sugeriu uma diretriz própria que, dentre diversas especificidades da obstetrícia, versa sobre a prevenção da aspiração pulmonar e sua relação com a oferta de líquidos claros e alimentos sólidos durante o trabalho de parto. A diretriz afirma que líquidos como: água, suco de fruta sem polpa, bebidas gaseificadas, chás claros, café e bebidas isotônicas podem ser ingeridos em quantidades moderadas até duas horas antes de cesáreas eletivas.

Ressalta-se que essas recomendações são direcionadas a mulheres em situação de trabalho de parto sem intercorrências ou com baixo risco de complicação. Em caso de pacientes com obesidade mórbida, diabetes, vias aéreas difíceis para intubação ou ainda aquelas que possuem grandes chances de evoluir para um procedimento cirúrgico de emergência devem ser avaliadas individualmente pela equipe ${ }^{14}$.

No mês de outubro de 2015, no Encontro Anual de Anestesiologistas promovido pela ASA, foi rediscutida essa temática, sugerindo que o consumo de uma refeição leve durante o trabalho de parto pode influenciar positivamente nos resultados do parto, favorecendo o aporte calórico da mulher e do feto e impedindo o desenvolvimento de acidose metabólica no binômio ${ }^{15}$.

Outra prática frequentemente utilizada de modo inadequado é a transferência da parturiente para a sala de parto no início do segundo estágio do parto, também chamado período expulsivo. Essa ação implica obrigatoriamente em colocar a mulher para parir em posição litotômica, mesmo que desde 1996 esta posição não seja mais recomendada (OMS) ${ }^{4}$. O Inquérito Nascer no Brasil encontrou que 92\% das mulheres ainda passam pelo período expulsivo nessa posição ${ }^{12}$.

Apesar de ser um direito da mulher, a prática da analgesia está classificada na Categoria $D$, uma vez que vem sendo utilizada com pouco critério, principalmente nos serviços privados. Em revisão sistemática realizada em 2011 demonstrou que apesar de reduzir a sensação dolorosa, a analgesia está relacionada ao aumento do risco do parto instrumental. ${ }^{16}$ No Sul do Brasil o índice de analgesia encontra-se em torno de $28,7 \%{ }^{12}$. Deste modo, pode-se aceitar que os indicadores da maternidade se encontram num limiar ótimo quando comparados aos dados nacionais.

Em relação à prática da episiotomia, nesse estudo observou-se uma queda de 50\% nos indicadores de 2014 para 2015. Contudo, em estudo publicado pela Federação Brasileira de Ginecologia e Obstetrícia (FEBRASGO) salientou-se que apesar de alguns tratados de obstetrícia recomendarem a realização desta prática em algumas situações, é importante que sejam publicados mais estudos clínicos randomizados para sustentá-la ${ }^{17}$.

Quanto aos métodos de alívio da dor no processo de parto, a porcentagem de mulheres que têm acesso a essas práticas vem ao encontro do que é recomendado pela OMS4, sendo, deste modo, um indicador classificado na categoria A (práticas demonstradamente úteis e que devem ser encorajadas). A partir do banco de dados do Inquérito Nascer no Brasil foi demonstrado que $74,2 \%$ das mulheres teve acesso a algum método não farmacológico para alívio da dor e desconforto durante o trabalho de parto ${ }^{18}$.

Dentre os métodos não farmacológicos utilizados estão o banho de aspersão (80\%), exercício na bola suíça (72\%), massagem (78\%), música $(76 \%)$ e penumbra (82\%). Um estudo realizado em uma casa de parto no interior de São Paulo, onde os partos também são atendidos por enfermeiras obstétricas, demonstrou dados semelhantes, principalmente em relação ao banho de aspersão $(84 \%)^{19}$. As taxas de uso da bola e da massagem foram um pouco mais baixas se comparadas aos dos indicadores na pesquisa aqui apresentada, mas ainda assim estão de acordo com o recomendado pela $\mathrm{OMS}^{4}$.

Apesar de ser utilizada em 76\% dos partos atendidos em 2015, não há evidências de que o emprego da música no trabalho de parto interfira significativamente na redução da 
sensação dolorosa, assim como foi demonstrado em revisão sistemática de $2011^{20}$.

A penumbra também foi considerada neste estudo como um método não farmacológico para alívio da dor. Para o organismo humano, a ausência ou diminuição de luz implica na produção da melatonina, que está diretamente relacionada à promoção do sono e estímulo da sexualidade ${ }^{21}$. Alguns estudos relacionam ainda a indução do sono à endorfina e outros hormônios femininos ${ }^{22,23}$. Vale ressaltar que a endorfina atua diretamente na inibição da dor durante o trabalho de parto, uma vez que é considerado um opiáceo natural. Assim, é possível considerar a penumbra como um método de alívio da dor, ainda que haja escassez de estudos nesta temática.

A taxa de deambulação é classificada como item separado dos métodos não farmacológicos ${ }^{24}$, entretanto, deve-se considerar a prática da livre deambulação também como um método para alívio da dor e do desconforto, uma vez que há menor compressão dos grandes vasos (aorta e veia cava) pelo útero gravídico, promovendo melhora no fluxo sanguíneo e oxigenação. A posição em pé proporciona ainda descompressão e alívio da região lombar e acelera o processo do trabalho de parto ${ }^{25}$.

Tanto a deambulação como o banho de aspersão, a bola e a massagem são descritas no manifesto pelo Parto Ativo, no qual as mulheres grávidas são encorajadas a adotar posições verticais durante o trabalho de parto a fim de favorecer a evolução fisiológica do mesmo, assim como impactar positivamente na qualidade e segurança do parto para mãe e bebê, pois também influenciam na liberação de hormônios como ocitocina e endorfina, os quais são fundamentais durante o processo do parto. ${ }^{25}$

As entrevistas propiciaram conhecer a percepção das enfermeiras em relação às práticas monitoradas nos indicadores. É evidente que a inserção da Enfermeira Obstétrica teve influência direta na assistência ao parto e nascimento e que, apesar de ter sido um processo gradativo, foi decisivo para a mudança do modelo de atendimento na instituição ${ }^{26}$.

A mudança de modelo assistencial citada nas entrevistas pode ser discutida a partir dos seguintes modelos: tecnocrático, humanístico e holístico ${ }^{27,28}$.

São considerados 12 pressupostos no modelo tecnocrático: 1-separação corpomente; 2-o corpo como máquina; 3- o paciente como objeto; 4-alienação do médico em relação ao paciente; 5-diagnóstico e tratamento de fora para dentro; 6-organização hierárquica e padronização de cuidados; 7-autoridade e responsabilidade inerente ao médico e não ao paciente; 8-supervalorização da ciência e da tecnologia dura; 9-intervenções agressivas com ênfase em resultados de curto prazo; 10-a morte como derrota; 11-um sistema dirigido pelo lucro e 12-intolerância a outras modalidades ${ }^{27}$.

Esse modelo tem características tão fortes e está enraizado de tal forma na sociedade, que acaba gerando um ambiente de estresse e angústia para os profissionais que tentam confrontá-lo, assim como foi colocado pelas entrevistadas. Ele é ensinado dentro dos cursos de graduação e reforçado nos programas de residência médica ${ }^{27}$. Nesse sentido, os grupos 1 e 2 deste estudo apontam relação direta entre as temáticas da formação e do modelo de atenção.

Contrapondo esse modelo, surgem os 12 pressupostos do modelo humanístico ${ }^{27}$ /humanista ${ }^{1}$. São eles: 1-conexão corpo-mente; 2-o corpo como organismo; 3-o paciente como sujeito relacional; 4-conexão e carinho entre médico e paciente; 5-diagnóstico e cura de fora para dentro e de dentro para fora; 6-balanço entre os desejos da instituição e do indivíduo; 7 informação, tomada de decisões e responsabilidade compartilhadas entre 0 médico e o paciente; 8-ciência e tecnologia contrabalançada com o humanismo; 9-foco na prevenção da doença; 10-a morte como resultado aceitável; 11-cuidados dirigidos pela compaixão e 12-mente aberta para outras modalidades.

Muito vem sendo discutido sobre esse modelo na assistência à saúde, principalmente no âmbito do Sistema Único de Saúde (SUS) ${ }^{4}$. Para as depoentes, a assistência prestada pela Enfermeira Obstétrica está, em sua essência e formação, relacionada a esse modelo, uma vez que se considera a mulher como centro do cuidado e que, ao tornar-se corresponsável por sua saúde, ela também se torna capaz de decidir sobre o seu corpo.

0 modelo holístico sugere também 12 pressupostos, os quais contemplam e enriquecem o modelo humanístico. 1-unicidade de corpo-mente e espírito; 2-o corpo é um sistema de energia interligado com outros sistemas de energia; 3-cura da pessoa em sua integralidade em um contexto de vida como um todo; 4-unidade essencial entre médico e cliente; 5-diagnóstico e cura de dentro para fora; 6-estrutura organizacional em rede que facilita a individualização da assistência; 7autoridade e responsabilidade inerente a cada indivíduo; 8-ciência e tecnologia colocadas a serviço do indivíduo; 9-focalização, a longo prazo, na criação e manutenção da saúde e do bem-estar; 10-a morte é um processo; 11-a cura é o foco e, por fim, 12-abarca múltiplas modalidades de cura ${ }^{27-28}$.

É equivocado considerar que os modelos citados estão engessados ${ }^{1}$. Assim como observado nos depoimentos, as Enfermeiras 
Obstétricas citam elementos dos três modelos de maneira harmônica e ponderada. Os profissionais da obstetrícia contemporânea têm a possibilidade de mesclar paradigmas específicos de cada modelo, entrelaçando-os de tal forma a criar um sistema de cuidado revolucionário considerando a miscigenação cultural da sociedade atual ${ }^{27}$.

Assim, quando as entrevistadas versam sobre a postura dos profissionais de saúde e disposição para encarar a mudança, fica claro que a mesma virá quando cada um se propuser a mudar um pouco de si dentro da prática assistencial, por esta razão esse processo é tão lento e gradual.

Relacionar e discutir o modelo de atenção com a postura dos profissionais tornase necessário quando a necessidade desenfreada de medicalizar eventos hospitalares impossibilita que equipe de saúde e usuário tenham uma relação de proximidade e confiança, o que acaba gerando relações conflituosas ${ }^{28}$.

Considerando que no universo da atenção obstétrica os protagonistas da assistência são a mulher e o bebê, é possível vislumbrar um cenário próximo àquele imaginado por Davis-Floyd ${ }^{27}$, no qual elementos pontuais de cada modelo são convocados para promover uma assistência justa e segura. Isso fica evidente quando surge na fala das Enfermeiras Obstétricas que o seu papel é garantir que a mulher ocupe de fato o lugar de protagonista, e que ao garantir o direito a informação e espaço para decidir sobre seu corpo, acaba promovendo também, além dos benefícios para evolução do trabalho, maior satisfação da mulher, uma vez que ela exerce sua liberdade e poder de escolha ${ }^{29}$.

É possível afirmar que o grau de satisfação da mulher está diretamente relacionado à presença da Enfermeira Obstétrica no trabalho de parto e parto, fato que pode trazer a reflexão de que os serviços precisam dispor de EOs em quantidades suficientes para atender a demanda de parturientes $^{29}$.

\section{CONCLUSÃO}

Esta pesquisa permitiu obter um panorama da assistência sob a ótica da enfermeira obstétrica. Há estudos que demonstram a satisfação da mulher, os benefícios e malefícios de determinadas práticas e rotinas, mas as vozes dessas profissionais, em sua maioria mulheres, não são tão comumente escutadas, apesar de seu envolvimento direto no processo de mudança do modelo de atenção obstétrica.

No universo da maternidade estudada, ficou evidente que o processo de inserção dessas profissionais, apesar de ter sido inicialmente conflituosa, promoveu avanços irreversíveis na prática do cuidado obstétrico da instituição. Ao inserir uma nova categoria profissional dentro de um serviço podem surgir dificuldades no âmbito das relações interpessoais, contudo, o apoio da gestão e a criação de protocolos permitiram que as enfermeiras obstétricas demonstrassem com mais segurança e autonomia a qualidade do seu trabalho.

Essas profissionais conquistaram o espaço e a confiança da equipe e da comunidade, promovendo um impacto positivo na qualidade da assistência prestada na maternidade. 0 comprometimento delas no cenário da assistência permitiu ainda a criação e qualificação dos protocolos institucionais, fazendo com que questões emblemáticas referentes à assistência fossem discutidas em conjunto com as equipes.

Os dados apresentados mostram que a partir do momento em que as enfermeiras obstétricas começaram a atender a maioria dos partos normais, uma série de outras práticas benéficas e cientificamente comprovadas e recomendadas tiveram aumento em seus índices, demonstrando que a atuação dessas profissionais promoveu impacto positivo na qualidade da assistência das mulheres e seus bebês.

Porém, é importante reconhecer que o jejum, ainda utilizado na instituição, precisa ser superado. Sugere-se à instituição conhecer as evidências nacionais e internacionais mais recentes acerca da temática e discutir e reformular o protocolo da maternidade neste sentido.

Outra questão importante é em relação à formação dos profissionais em obstetrícia. Enquanto a formação permanecer arraigada no modelo tecnocrático, continuará havendo retrocessos em diversos aspectos no atendimento ao parto e, infelizmente, não haverá grandes contribuições para a prevenção e redução da morbimortalidade materna e infantil. O espaço acadêmico é formador de opinião e celeiro do conhecimento e deveria, portanto, ser o berço da mudança do modelo de atenção.

Este estudo tem como limitação a pesquisa em uma única instituição, pela qual se sugere estudos comparativos. Sugere-se ainda que a renovação constante do conhecimento com base em evidências científicas, a defesa da autonomia e do direito das mulheres na escolha da melhor forma de parir são caminhos importantes a ser buscados pelos profissionais que desejam alcançar a humanização da assistência ao parto e consequentemente a mudança do panorama da atenção obstétrica no Brasil. 


\section{REFERÊNCIAS}

1. Ministério da Saúde (Br). Universidade Estadual do Ceará. Humanização do parto e do nascimento [Internet]. Brasília, DF: Ministério da Saúde; 2014 [citado em 26 fev 2016]. 465p. (Caderno HumanizaSUS; v. 4). Disponível em: http://www.redehumanizasus.net/sites/default /files/caderno_humanizasus_v4_humanizacao_p arto.pdf

2. Ministério da Saúde (Br), Secretaria de Atenção à Saúde, Departamento de Ações Programáticas Estratégicas. Política Nacional de Atenção Integral à Saúde da Mulher: princípios e diretrizes. 2ed. Brasília, DF: Ministério da Saúde; 2011 [citado em 15 ago 2016]. Disponível em: http://bvsms.saude.gov.br/bvs/publicacoes/poli tica_nac_atencao_mulher.pdf

3. Ministério da Saúde (Br). Portaria no 1.459 , de 24 de junho de 2011. Institui no âmbito do Sistema Único de Saúde - SUS - a Rede Cegonha [Internet]. Brasília, DF: Ministério da Saúde; 2011 [citado em 26 fev 2016]. Disponível em: http://bvsms.saude.gov.br/bvs/saudelegis/gm/ 2011/prt1459_24_06_2011.html

4. Organização Mundial da Saúde. Maternidade segura: guia prático para o parto normal. Genebra: OMS; 1996.

5. Conselho Federal de Enfermagem (Brasil). Resolução no 0516/2016. Normatiza a atuação e a responsabilidade do Enfermeiro, Enfermeiro Obstetra e Obstetriz na assistência às gestantes, parturientes, puérperas e recém-nascidos nos Serviços de Obstetrícia, Centros de Parto Normal e/ou Casas de parto e outros locais onde ocorra essa assistência; estabelece critérios para registro de títulos de Enfermeiro Obstetra e Obstetriz no âmbito do Sistema COFEN/Conselhos Regionais de Enfermagem, e dá outras providências [Internet]. Brasília, DF: COFEN; 2016 [citado em 02 abr 2017]. 7 p. Disponível em: http://www.cofen.gov.br/wp-

content/uploads/2016/06/RES.-COFEN-5162016.pdf

6. Creswell JW, Clark VLP. Pesquisa de métodos mistos. 2ed. Porto Alegre: Penso; 2013.

7. Bardin L. Análise de conteúdo. Reimpr. 1ed Lisboa: Edições 70; 2016. 282p.

8. Presidência da República (Brasil). Lei $\mathrm{n}^{\mathrm{o}}$ 11.108, de 7 de abril de 2005. Altera a Lei 8.080, de 19 de setembro de 1990, para garantir às parturientes o direito à acompanhante durante o trabalho de parto, parto e pós parto imediato, no âmbito do Sistema Único de Saúde-SUS [Internet]. D.O.U., Brasília, DF, 8 abr 2005 [citado em 02 abr 2017]. Disponível

em: http://www.planalto.gov.br/ccivil_03/_Ato20042006/2005/Lei/L11108.htm

9. Ministério da Saúde (Br). Portaria no 371, de 7 de maio de 2014. Institui diretrizes para a organização da atenção integral e humanizada ao recém-nascido (RN) no Sistema Único de Saúde (SUS) [Internet]. Brasília, DF: Ministério da Saúde; 2014 [citado em 02 abr 2017]. Disponível em: http://bvsms.saude.gov.br/bvs/saudelegis/sas/ 2014/prt0371_07_05_2014.html
10. Mercer JS, Erickson-Owens DA, Graves B, Haley MM. Práticas baseadas em evidências para a transição de feto a recém-nascido. Tempus [Internet]. 2010 [citado em 07 jan 2017]; 4(4): p.173-89. Disponível em:

http://www.

tempusactas.unb.br/index.php/tempus/article/v iewFile/845/808

11. Porto AMF, Amorim MMR, Souza ASR. Assistência ao primeiro período do parto baseada em evidências. Femina. [Internet]. 2010 [citado em 18 nov 2016]; 38(10):527-37. Disponível em: http://bhpelopartonormal.pbh.gov.br/estudos_ci entificos/arquivos/artigo_femina_assistencia_ao_ parto_parte_I.pdf

12. Leal MC, Pereira APE, Domingues RMSM, Theme Filha MM, Dias MAB, Nakamura-Pereira M, et al. Intervenções obstétricas durante o trabalho de parto e parto em mulheres brasileiras de risco habitual. Cad Saúde Pública. [Internet]. 2014 [citado em 02 abr 2017]; 30(Supl):17-47. DOI: 10.1590/0102-311X00151513

13. Verheijen EC, Raven JH, Hofmeyr GJ. Fundal pressure during the second stage of labour. Cochrane Database Syst Rev. [Internet]. 2009 [citado em 02 abr 2017]; 4(CD006067). Disponível em: https://www.cochranelibrary.com/cdsr/doi/10. 1002/14651858.CD006067.pub2/epdf/full. DOI: 10.1002/14651858.CD006067.pub2

14. American Society of Anesthesiologists Tasks Force on Obstetric Anesthesia. Practice Guidelines for Obstetric Anesthesia: an updated report by the American Society of Ansthesiologists Task Force on Obstetric Anesthesia. Anesthesiology. [Internet]. 2007 [citado em 02 abr 2017]; 106(4):843-63. Disponível

em: https://www.ncbi.nlm.nih.gov/pubmed/174139 23. DOI: $10.1097 / 01$.anes.0000264744.63275.10 15. American Society of Anesthesiologists. Most Healthy women would benefit from light meal during labor [Internet]. News. San Diego; nov 6, 2015 [citado em 31 ago 2015]. Disponível em: http://www.asahq.org/about-

asa/newsroom/news-releases/2015/11/eatinga-light-meal-during-labor

16. Anim-Somuah M, Smyth RM, Jones L. Epidural versus non-epidural or no analgesia in labour. Cochrane Database Syst Rev. [Internet]. 2011 [citado em 02 abr 2017]; 12(CD000331). Disponível

em: https://www.cochranelibrary.com/cdsr/doi/10. 1002/14651858.CD000331.pub3/full. DOI: 10.1002/14651858.CD000331.pub3

17. Amorim MMR, Porto AMF, Souza ASR. Assistência ao segundo e terceiro períodos do trabalho de parto baseada em evidências. Femina. [Internet]. 2010 [citado em 18 nov 2016]; 38(11):583-91. Disponível em: http://files.bvs.br/upload/S/01007254/2010/v38n11/a583-591.pdf

18. Sousa AMM, Souza KV, Rezende EM, Martins EF, Campos D, Lansky S. Práticas na assistência ao parto em maternidades com inserção de enfermeiras obstétricas, em Belo Horizonte, 
